\title{
Effect of changes in diet energy density on feed intake, milk yield and metabolic parameters in dairy cows in early lactation
}

\author{
N. I. Nielsen ${ }^{1 \dagger}$, N. C. Friggens ${ }^{1}$, T. Larsen ${ }^{1}$, J. B. Andersen ${ }^{1}$, M. O. Nielsen ${ }^{2}$ \\ and K. L. Ingvartsen ${ }^{1}$ \\ ${ }^{1}$ Danish Institute of Agricultural Sciences, Department of Animal Health, Welfare and Nutrition, Research Centre Foulum, PO Box 50, 8830 Tjele, Denmark \\ ${ }^{2}$ The Royal Veterinary and Agricultural University, Department of Animal and Veterinary Basic Sciences, Groennegaardsvej 7, 1870 Frederiksberg C, Denmark
}

(Received 27 February 2006; Accepted 30 October 2006)

\begin{abstract}
The purpose of this experiment was to investigate how early lactating cows adjust their metabolism and production to acute, but moderate changes in the energy density of the diet. Sixty dairy cows were randomly assigned to one of four treatments: two change-over groups ( $H N H$ and NHN) and two control groups ( $H H H$ and NNN), where $H$ and $N$ refer to a high and normal energy density in the total mixed ration (TMR), respectively. The experimental period covered the first 9 weeks post calving, which was split up in three 3-week periods. Thus, cows assigned to HNH or NHN shifted TMR in weeks 4 and 7 after calving while cows assigned to HHH or NNN were fed the same TMR for all 9 weeks. Results from cows on treatment HNH were compared with group $\mathrm{HHH}$ while cows on treatment NHN were compared with group NNN. When the diet changed from $\mathrm{N}$ to $\mathrm{H}$ and $\mathrm{H}$ to $\mathrm{N}$, cows increased and decreased their dry-matter intake (DMI), respectively compared with control groups. Cows adjusted milk yield accordingly to changes in DMI, although not always significantly. Energy-corrected milk yield was not significantly affected by any of the changes in the energy density of the diet but generally showed same tendencies as milk yield. Non-esterified fatty acids (NEFA), beta-hydroxybutyrate in blood and milk and triacylglycerol and glycogen content in the liver were not significantly affected by changes in the energy density of the diet, except from NEFA at one change. Glucose increased more when the diet changed from $\mathrm{N}$ to $\mathrm{H}$ and increased less when the diet changed from $\mathrm{H}$ to $\mathrm{N}$, compared with control groups, although not always significantly. Collectively, these results suggest that cows adjust their DMI and partly milk yield according to the energy density of the diet and therefore only limited effects were observed in physiological parameters.
\end{abstract}

Keywords: dairy cows, energy metabolism, metabolism, nutrient balance

\section{Introduction}

Ketosis and fatty liver are consequences of imbalance in the normal regulating physiological mechanisms (Herdt and Emery, 1992; Goff and Horst, 1997; Ingvartsen, 2006). Such metabolic imbalance is likely to be monitored in the future by means of in-line measurements of milk constituents (Mottram et al., 2002; Nielsen et al., 2005) or by small portable analytical devices for on-farm analyses of metabolites in blood (Andersen et al., 2002a; Perkins et al., 2005). It is therefore of interest to use the information from physiological parameters in blood and/or milk to make adjustments in the feeding on a group or individual level, in order to minimise the risk

\footnotetext{
${ }^{\dagger}$ E-mail: ncn@landscentret.dk
}

of metabolic diseases (Ingvartsen, 2006). However, knowledge is needed in relation to how these adjustments of feeding should be done.

It is known that a shift in the feeding intensity from ad libitum to restricted feeding can provoke a metabolic imbalance in early lactating cows characterised by significant changes in blood glucose, $\beta$-hydroxybutyrate (BHB) and non-esterified fatty acids (NEFA) despite reduced milk yield (Drackley et al., 1991; Veenhuizen et al., 1991; Nielsen et al., 2003). It is less clear what happens if early lactating cows fed ad libitum are shifted from a high to a lower energy density diet or vice versa, without restricting the feed allowance, and if such a change could reduce mobilisation of fat. The cow can respond to changes in feeding by changing dry-matter intake (DMI) and adjusting its partition of nutrients, i.e. by regulation of milk yield, 
body reserves or a combination of those two. Studies have shown that early lactating cows fed a high energy density diet ad libitum had a higher DMI and milk yield than cows fed a low energy density diet ad libitum (Friggens et al., 1998; Andersen et al., 2002b; McNamara et al., 2003) and that cows fed the low energy diet had the highest metabolic load assessed by metabolites in blood and liver tissue (Nachtomi et al., 1991; Andersen et al., 2002b). Therefore, changing early lactating cows' feeding from a high to a low energy density diet would be expected to decrease DMI and milk yield and impair the metabolism of the cow and vice versa for cows changing from low to high. However this has not been directly tested and quantified.

Further, there is an ongoing debate among advisors, farmers and researchers about how sensitive a cow is to changes in feeding in early lactation and it is repeatedly stated that abrupt changes in the diet should be avoided as it imposes a risk for reduced production and impaired metabolism (Friggens et al., 2004; Ingvartsen, 2006). Changing the energy density of a total mixed ration (TMR) from high to low in mid lactation decreases DMI and milk yield, while a shift from low to high increases DMI but only partly milk yield (Friggens et al., 1998). Friggens et al. (1998) did not measure physiological parameters, but their results suggest that storing energy became an important priority relative to milk production for cows that were fed a low energy density TMR in early lactation before the change to a high energy density TMR. In early lactation where nutrient partitioning, and thus metabolism, is towards milk production (Nielsen and Riis, 1993), it would seem less likely that additional energy would be channelled to body reserves, when changing the diet from low to high.

The purpose of this experiment was to investigate how early lactating cows adjust their intake, metabolism and production in response to acute changes in the energy density of the diet by measuring responses in physiological parameters in blood, milk and liver tissue, feed intake and milk production.

\section{Material and methods}

\section{Animals and design}

Four treatments were used in this study: two change-over groups ( $\mathrm{HNH}$ and $\mathrm{NHN}$ ) and two control groups ( $\mathrm{HHH}$ and $\mathrm{NNN}$ ), where $\mathrm{H}$ and $\mathrm{N}$ refer to a high and normal energy density in the TMR, respectively. The experimental period covered the first 9 weeks after calving, which was split up into three 3-week periods. Thus, cows assigned to HNH or NHN shifted TMR at weeks 4 and 7 after calving while cows assigned to HHH or NNN were fed the same TMR all 9 weeks. The cows were blocked in pairs $(\mathrm{HHH} v$. HNH and NNN v. NHN) according to parity (primiparous $(n=22)$ or multiparous $(n=38))$ within breed (Red Danish $(n=24)$, Danish Holstein $(n=22)$ or Danish Jersey $(n=14))$ and calving date (cows calved between August 2003 and April
2004). Further, Red Danish and Danish Holstein were blocked according to milking unit since they were mixed between two robotic milking units, while the Jerseys were milked in their own unit. Cows were block-wise randomly assigned to treatments $\mathrm{HHH} / \mathrm{HNH}$ or NNN/NHN. The aim was to include 20 cows on each treatment but due to unfortunate circumstances (severe mastitis, ketosis, displaced abomasums, leg problems, calving difficulties and cows not coping with the automatic milking system (AMS) or with the automatic feeding dispenser) and the fact that a whole block (two cows) was excluded if just one of the cows were sick, treatments NNN and NHN only included 10 animals each. Treatments $\mathrm{HHH}$ and $\mathrm{HNH}$ included 20 animals each, i.e. 60 cows were used in the statistical analyses.

\section{Milking}

The cows were housed in a loose housing system in three groups and each group was milked by an AMS (Voluntary Milking System, DeLaval, Tumba, Sweden). The number of cows in each group and milking unit was held as constant as possible during the trial period. Free cow traffic, i.e. cows had access the feeding dispensers without having to enter the AMS, was practised in all three groups. During the first 3 weeks of lactation, cows were fetched for milking if $>7 \mathrm{~h}$ had passed since their last milking. This was done twice daily; in the morning and in the afternoon. Likewise, cows in weeks 4 to 9 of lactation were fetched for milking if $>14 \mathrm{~h}$ had passed since their last milking.

\section{Feeding}

Pre-trial, i.e. 56 to 10 days before expected calving, cows were fed the same dry cow TMR ad libitum consisting of rapeseed meal (31), barley (37), dried sugar-beet pulp (molassed) (16), grass silage (223), maize silage (390), barley straw (271) and minerals and vitamins (32) $(\mathrm{g} / \mathrm{kg}$ dry matter (DM)). The dry cows had a DMI of approximately $8 \mathrm{~kg} /$ day for the large breeds (Holstein and Red Danish) and approximately $6 \mathrm{~kg} /$ day for Jerseys, which is in accordance with Danish feeding recommendations. Ten days before expected calving cows were moved to one of the three lactating groups where they had ad libitum access to the same TMR ( $\mathrm{H}$ or $\mathrm{N}$ ) as they were going to receive the first 3 weeks after calving. Heifers were moved to the lactating cow groups 3 weeks before expected calving and had access to the TMR they were going to receive in the first 3 weeks after calving. Cows were allowed $1 \mathrm{~kg}$ of concentrates (Table 2) per day pre-calving via the AMS, while heifers were allowed $2 \mathrm{~kg}$ in order to stimulate their interest for the milking unit. Cows and heifers calved in individual calving pens and were put back into their respective lactating groups 1 or 2 days after calving.

The TMRs were offered in feeding dispensers placed on weigh-cells in order to record the amount of feed consumed at every visit (Roughage Intake System, Insentec BV, Marknesse, Holland). Both TMRs were fed ad libitum and their ingredients and measured chemical composition 
are listed in Table 1. The allocation of TMRs $(\mathrm{H}$ or $\mathrm{N})$ to feeding dispensers was the same throughout the trial, i.e. cows that shifted TMR had to access other feeding dispenser than they were used to. Each feeding dispenser could in average be accessed by 2.5 cows and this was kept as constant as possible throughout the trial. The feeding dispensers were filled up four times daily and twice a week they were emptied for leftovers.

Besides the TMR, all lactating cows were allowed $3 \mathrm{~kg}$ of concentrates per day in the milking unit (Table 2). If a cow did not eat its ration the preceding day, it was transferred to the following day. However, only a maximum of $1.5 \mathrm{~kg}$ was allowed to be transferred to the following day. Leftovers of concentrates were weighed after each milking. Daily intakes of the TMR from the feeding dispenser and concentrates in the AMS were reduced to weekly means.

Digestible energy $(D E)$ was calculated according to the following equation: $\mathrm{DE}(\mathrm{MJ} / \mathrm{kg} \mathrm{DM})=24.237 \times$ digestible crude protein $+34.116 \times$ digestible crude fat $+17.3 \times$ digestible carbohydrate. The energy content is based on digestibility coefficients of organic dry matter in sheep at maintenance (Møller et al., 2005).

\section{Sampling of blood, milk and liver tissue}

All the procedures involving animals were approved by the Danish Animal Experiments Inspectorate and complied with the Danish Ministry of Justice Law no. 382 (June 10, 1987) and Acts 739 (December 6, 1988) and 333 (May 19, 1990) concerning animal experimentation and care of experimental animals. Blood samples were collected by puncture of the coccygeal vein/artery using heparinised Vacutainer tubes (BD Vacutainer Systems, Plymouth, UK). Plasma was harvested following

Table 1 Ingredients, measured chemical composition and calculated characteristics of the total mixed rations with normal $(\mathrm{N})$ or high $(\mathrm{H})$ energy content

\begin{tabular}{|c|c|c|}
\hline & $\mathrm{N}$ & $\mathrm{H}$ \\
\hline \multicolumn{3}{|l|}{ Ingredients (g/kg DM) } \\
\hline Rapeseed meal (mechanically ext.) & 100 & 170 \\
\hline Barley & 121 & 207 \\
\hline Dried sugar-beet pulp (molassed) & 52 & 88 \\
\hline Grass silage & 239 & 173 \\
\hline Maize silage & 465 & 342 \\
\hline Urea & 6 & 5 \\
\hline Minerals and vitamins & 17 & 15 \\
\hline \multicolumn{3}{|l|}{ Chemical composition (g/kg DM) } \\
\hline Crude protein & 147 & 154 \\
\hline Crude fat & 42 & 51 \\
\hline Sugar & 30 & 37 \\
\hline Starch & 207 & 216 \\
\hline Neutral-detergent fibre & 358 & 334 \\
\hline Ash & 75 & 70 \\
\hline Digestible energy $(\mathrm{MJ} / \mathrm{kg} \mathrm{DM})^{\dagger}$ & 13.4 & 14.0 \\
\hline
\end{tabular}

\footnotetext{
${ }^{\dagger}$ See Material and methods.
}

Table 2 Ingredients, measured chemical composition and calculated characteristics of the concentrate offered in the automatic milking unit in the weeks just prior to calving and during lactation

Concentrates

\begin{tabular}{lc}
\hline Ingredients (g/kg DM) & \\
Sunflower meal (mechanically ext.) & 150 \\
Distillers' grain, maize based & 150 \\
Dried sugar-beet pulp & 150 \\
Wheat & 124 \\
Rapeseed meal (mechanically ext.) & 104 \\
Soya-bean hulls & 91 \\
Wheat bran & 90 \\
Dried grass & 80 \\
Molasses, cane & 30 \\
Vegetable fat & 13 \\
Minerals and vitamins & 18 \\
Chemical composition (g/kg DM) & \\
Crude protein & 219 \\
Crude fat & 55 \\
Sugar & 83 \\
Starch & 102 \\
Neutral-detergent fibre & 293 \\
Ash & 79 \\
Digestible energy (MJ/kg DM) & ${ }^{\dagger}$ \\
\hline \hline
\end{tabular}

${ }^{\dagger}$ See Material and methods.

centrifugation at $2000 \times \mathbf{g}$ for $20 \mathrm{~min}$ at $4^{\circ} \mathrm{C}$ and stored at $-18^{\circ} \mathrm{C}$ until analysis. Samples were collected twice weekly (Monday and Thursday) for the first 9 weeks after calving between 1300 and $1400 \mathrm{~h}$.

At each milking, a proportional sample of composite milk was collected and distributed automatically into two tubes: one for analysis of fat, protein and lactose and another for analysis of $\mathrm{BHB}$. Both milk tubes were pre-treated with a Bronopol $\left(\mathrm{C}_{3} \mathrm{H}_{6} \mathrm{BrNO}_{4}\right.$, Merck-Schuchardt, Hohenbrunn, Germany) solution to obtain 200 p.p.m. in the final volume. The automatic milk samplers were emptied of samples every morning and afternoon and milk samples were kept at $4^{\circ} \mathrm{C}$ until analysis. Milk samples were analysed within 1 to 3 days.

Liver biopsies were taken in weeks 3, 4 and 6 after calving. Liver biopsies (approx. $20 \mathrm{mg}$ wet weight per biopsy) were obtained through an incision on the right side of the cow between 10th and 11th rib where it crossed a line from the hip (tuber coxae) to the upper part of the right front leg (mid humerus). Before taking the biopsies, a $5 \times 5 \mathrm{~cm}$ area was shaved and disinfected whereupon a 10-ml local anaesthesia (Lidocaine, Skanderborg Pharmaceuticals, Skanderborg, Denmark) was given. After a minimum of $10 \mathrm{~min}$, a $0.5-\mathrm{cm}$ incision in the skin was made. Liver biopsies were taken through this incision using a PRO-MAG biopsy instrument with 14 gauge $\times 10 \mathrm{~cm}$ needles (MDTECH, Florida, USA). The biopsies were immediately frozen in liquid nitrogen and transported to the laboratory where the biopsies were stored at $-80^{\circ} \mathrm{C}$ until analyses. 


\section{Laboratory analyses}

BHB in plasma was determined by increasing absorbance due to the production of $\mathrm{NADH}^{+}$at an alkaline $\mathrm{pH}$ of 8.5 in the presence of BHB-dehydrogenase. The setup involved oxamic acid in the reagent to inhibit lactate dehydrogenase as proposed by Harano et al. (1985). Analyses of NEFA were performed using the acyl-CoA synthetase - acyl-CoA oxidase (ACS-ACOD) method as prepared by Wako Chemicals (Wako Chemicals, Virginia, USA). Concentrations and volumes of reagents were slightly modified to optimise the procedure for use on an autoanalyser. Glucose was determined by the combined hexokinase and glucose-6-phosphate dehydrogenase method as standardised by ADVIA ${ }^{\circledR}$ Chemistry System (Bayer Corporation, New York, USA). Analyses of BHB, NEFA, and glucose in plasma were all performed using an autoanalyser (ADVIA ${ }^{\mathrm{TM}} 1650$ Chemistry System, Bayer Corporation, New York, USA). The inter- and intra-assay coefficients of variation were $<3 \%$ for low and high controls for all metabolites.

All milk samples obtained were analysed for fat, protein and lactose on a CombiFoss 4000 (Foss Electric A/S, Hillerød, Denmark). Milk samples from the first milking of a cow within a day were analysed for BHB. These milk samples were pipetted and diluted using a Biomek $2000^{\odot}$ automated system (Laboratory Automation Workstation, Beckman Coulter, USA). Reagents for the BHB assay were added in the automated system as well as in the fluorometer (Fluostar ${ }^{\odot}$, BMG Labtechnologies, Germany). Further details on the analysis procedure are given in Larsen and Nielsen (2005).

Liver biopsies were homogenised, centrifuged and the supernatant was analysed for glycogen content based on an enzymatic colorimetric kit modified to fit small tissue samples and to be performed on an autoanalyser. Liver triacylglycerol (TAG) content was determined after lipid extraction from liver biopsies. The TAG analysis was likewise based on an enzymatic colorimetric kit performed on an autoanalyser. The analysis procedures of liver TAG and glycogen are described in more detail by Andersen et al. (2005).

Calculation of daily milk yield, daily milk composition and daily energy corrected milk yield

The AMS recorded milk yield and time of each milking. Daily milk yields and milk composition were calculated for each cow from midnight to midnight, i.e. milk yields and milk composition from milkings that overlapped 2 days were split up according to milk produced pre- and post midnight assuming a linear relationship between milk yield and interval since last milking (Friggens and Rasmussen, 2001). Daily energy-corrected milk yield (ECM) was calculated according to the equation: $\mathrm{kg}$ milk $\times((383 \times \mathrm{F} \%+242 \times \mathrm{P} \%+163.2 \times \mathrm{L} \%) / 3140)$

(Sjaunja et al., 1990), which assumes a standard energy content of milk of $3.14 \mathrm{MJ} / \mathrm{kg}$. Daily milk yield, milk composition (fat, protein, lactose and BHB) and ECM were reduced to weekly means.
Calculation of responses and statistical analyses

For each variable two responses were calculated within cow: a response from week 3 to weeks $5+6$ and from week 6 to weeks $8+9$. The level of each variable at weeks $5+6$ and weeks $8+9$ was calculated as simple means and the responses were calculated as: (weeks $5+6-$ week 3 ) and (weeks $8+9-$ week 6 ). The only exception was liver TAG and glycogen where biopsies were taken in weeks 3, 4 and 6 after calving. Responses were therefore calculated as: (week 4 - week 3) and (week 6 week 3). The effects of HHH v. HNH and NNN v. NHN were analysed separately using a model that included parity (primiparous, multiparous) and feeding regime $(\mathrm{HHH}, \mathrm{HNH}$ or NNN, NHN) as fixed effects and a covariate (continuous variable), i.e. the level of the response variable in week 3 or 6 . The covariate was included in the model because the response in most variables was dependent upon the initial level, i.e. the level in week 3 after calving. This starting level in week 3 tended to differ between treatments, especially for NEFA (Figure 2), despite the fact that cows on treatments $\mathrm{HHH} / \mathrm{HNH}$ and NNN/NHN were treated equally the first 3 weeks after calving. So in order to adjust for these differences between cows on the same diet in week 3 , a covariate was included. The reason for including a covariate when analysing the response from week 6 to weeks $8+9$ was to eliminate any effects that were caused by the change in TMR in week 4 and any differences still remaining between treatment groups due to the differences observed in week 3.

Breed (Red Danish, Danish Holstein, Danish Jersey) and interactions between breed, treatment and parity were initially included in the model without showing any significant effects for the response variables and were therefore omitted from the final model. Milking unit confounded with breed because Jersey cows were milked in their own unit and milking unit was therefore not included in the final model. Data were analysed using the MIXED procedure of SAS (SAS Institute, 1999).

\section{Results}

The results for the four different feeding regimes on DMI, milk yield and physiological parameters are presented for all weeks as simple means in Figures 1 to 3, i.e. not covariate-adjusted. As described in Material and methods, covariate-adjusted responses to feeding regimes from weeks 3 to $5+6$ and 6 to $8+9$ were calculated and these are presented in Tables 3 and 4 together with statistical results.

Dry-matter and energy intake, milk production and milk composition

Cows responded with decreased DMI when changing from diet $\mathrm{H}$ to $\mathrm{N}$ and increased DMI when changing from $\mathrm{N}$ to $\mathrm{H}$ although the response from week 6 to weeks $8+9$ was not significantly different between treatments $\mathrm{HHH}$ and 

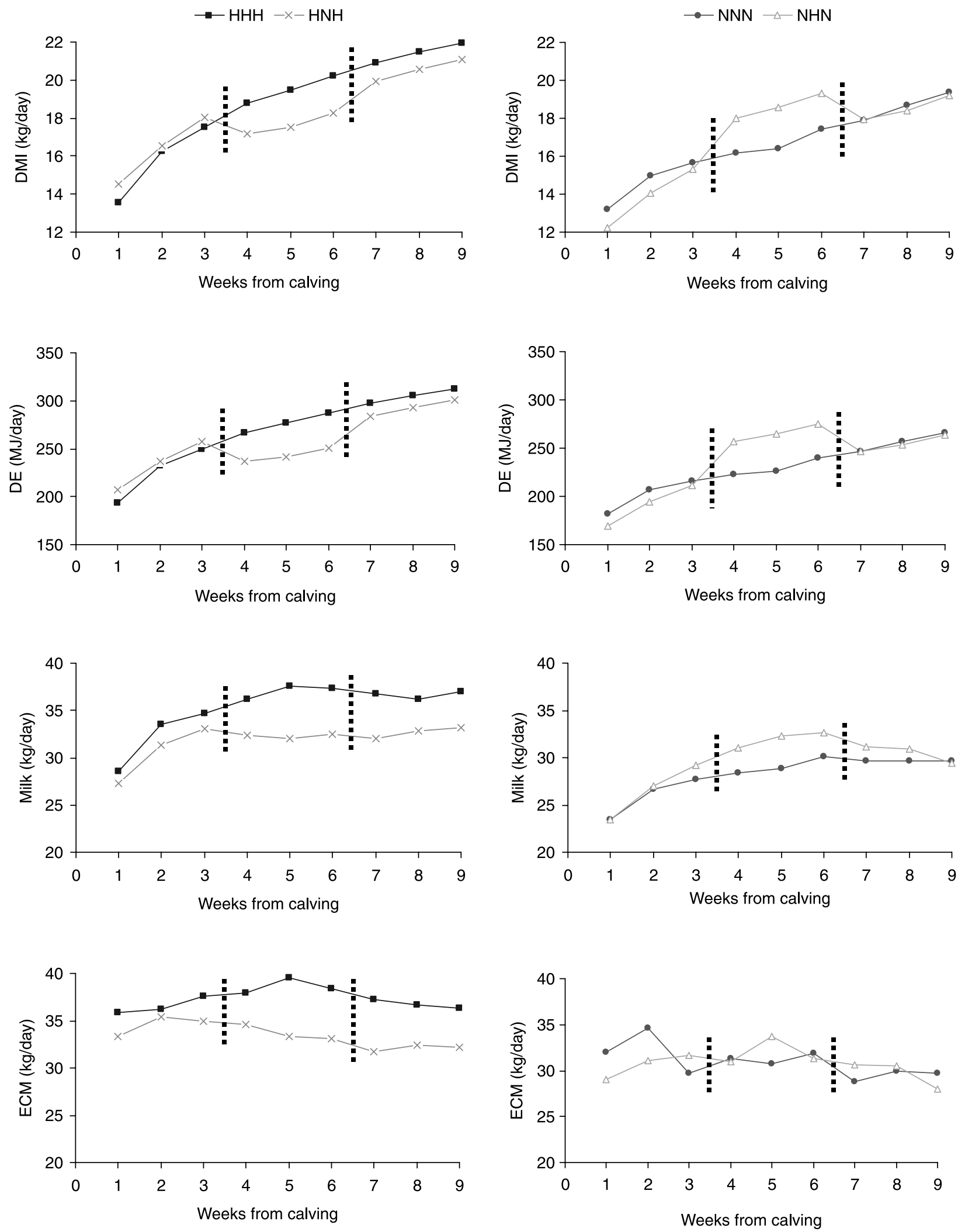

Figure 1 Dry-matter intake (DMI), digestible energy (DE), milk yield and energy-corrected milk yield (ECM) (means) during the first 9 weeks of lactation. The dotted vertical lines indicate a shift in total mixed ration from $\mathrm{H}$ (high energy) to $\mathrm{N}$ (normal energy) or vice versa for treatments $\mathrm{HNH}$ and NHN. Standard errors for $\mathrm{HHH}, \mathrm{HNH}, \mathrm{NNN}$ and NHN were for DMI: 0.32, 0.31, 0.48 and 0.45; DE: 4.5, 4.4, 6.5 and 6.2; milk yield: 0.8, 0.7, 1.1 and 1.1; ECM: 0.8, $0.7,1.1$ and 1.0. All observations within treatment were used in the calculation of the standard error. Note that comparisons between HHH/HNH and NNN/NHN are difficult due to a higher proportion of Jersey and primiparous cows on treatments NNN and NHN. 
Nielsen, Friggens, Larsen, Andersen, Nielsen and Ingvartsen
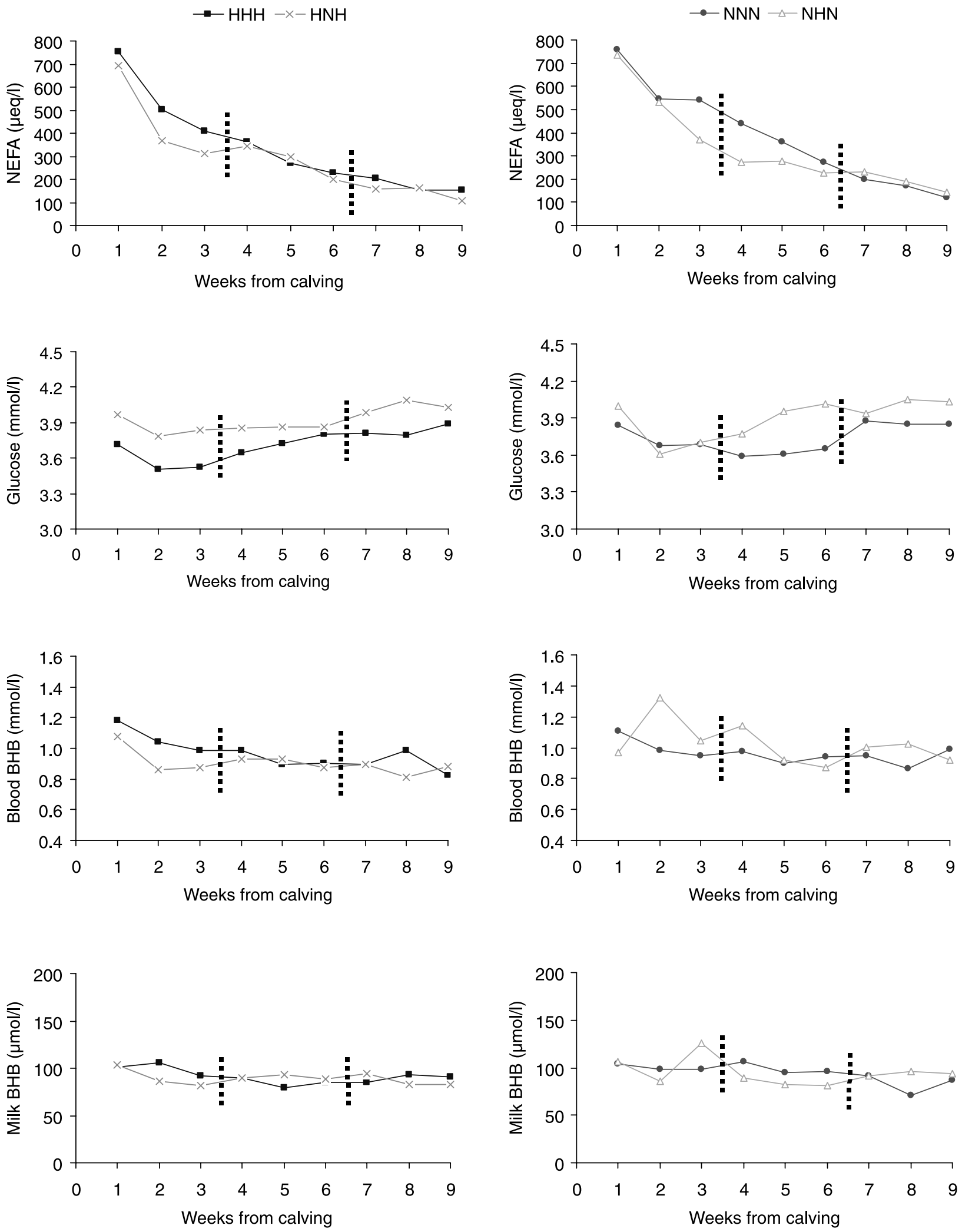

Figure 2 Concentrations (means) of non-esterified fatty acids (NEFA), glucose and beta-hydroxybutyrate (BHB) in blood and milk during the first 9 weeks of lactation. The dotted vertical lines indicate a shift in total mixed ration from $\mathrm{H}$ (high energy) to $\mathrm{N}$ (normal energy) or vice versa for treatments $\mathrm{HNH}$ and NHN. Standard errors for HHH, HNH, NNN and NHN were for NEFA: 21, 19, 32 and 28; glucose: 0.04, 0.03, 0.04 and 0.05; BHB in plasma: 0.02, $0.02,0.03$ and 0.04 ; BHB in milk: 3, 3, 5 and 4 . All observations within treatment were used in the calculation of the standard error. Note that comparisons between $\mathrm{HHH} / \mathrm{HNH}$ and NNN/NHN are difficult due to a higher proportion of Jersey and primiparous cows on treatments NNN and NHN. 

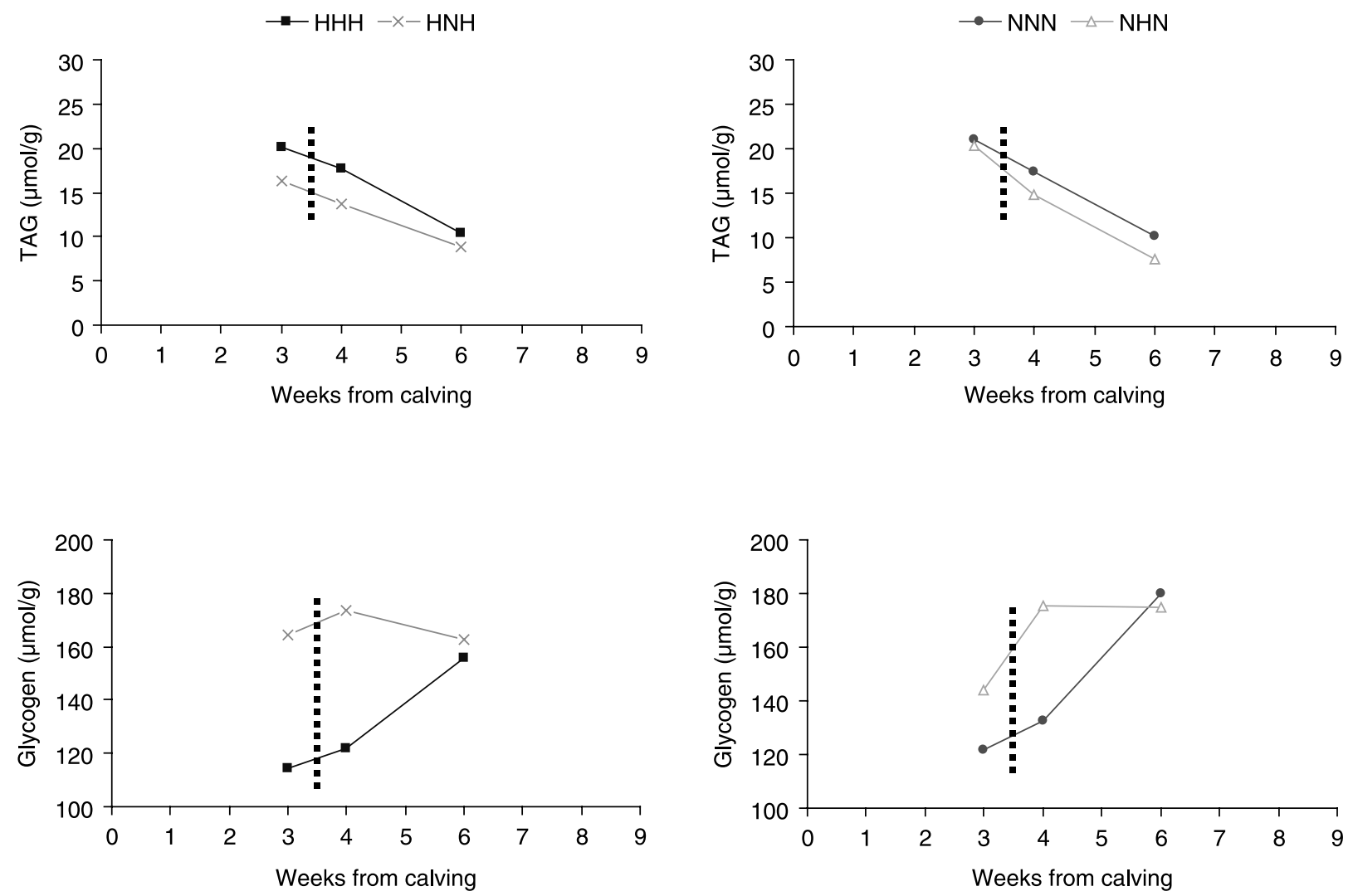

Figure 3 Concentrations (means) of triacylglycerol (TAG) and glycogen in the liver in weeks 3, 4 and 6 after calving. The dotted vertical line indicates a shift in TMR from $\mathrm{H}$ (high energy) to $\mathrm{N}$ (normal energy) for treatment $\mathrm{HNH}$ and a shift from $\mathrm{N}$ to $\mathrm{H}$ for treatment $\mathrm{NHN}$. Standard errors for HHH, HNH, NNN and NHN were for TAG: 1.5, 1.6, 1.9 and 2.2; glycogen: 9, 9, 13 and 11. All observations within treatment were used in the calculation of the standard error. Note that comparisons between $\mathrm{HHH} / \mathrm{HNH}$ and NNN/NHN are difficult due to a higher proportion of Jersey- and primiparous cows on treatments NNN and NHN.

HNH (Tables 3 and 4). Intake of predicted DE followed the same pattern as DMI but in contrast to DMI there was a significant positive response in DE when the diet was changed from $\mathrm{N}$ to $\mathrm{H}$ for cows on treatment $\mathrm{HNH}$. The decrease in DMl from week 3 to weeks $5+6$ for cows on treatment $\mathrm{HNH}$ was associated with a significant negative response in milk yield, but not ECM, compared with cows on $\mathrm{HHH}$. From week 6 to weeks $8+9$ the milk yield of cows shifting from $\mathrm{N}$ to $\mathrm{H}$ (treatment $\mathrm{HNH}$ ) did not respond significantly differently from cows on $\mathrm{HHH}$, which was in agreement with the non-significant change in DMI between those treatments. The significant effect on DMI of shifting cows from $\mathrm{N}$ to $\mathrm{H}$ and then back to $\mathrm{N}$ (treatment NHN) did not result in any significant effects on milk yield and ECM. However, the trend in milk yield response was as expected since milk yield increased by $3.3 \mathrm{~kg}$ for cows shifting from $\mathrm{N}$ to $\mathrm{H}$ and decreased by $2.3 \mathrm{~kg}$ when the cows changed back to $\mathrm{N}$ (Table 4). The content of fat, protein and lactose in milk was not significantly influenced by the shifts in energy density of the diet. This was the case for both $\mathrm{HNH}$ and NHN and at both shifts at weeks 4 and 7 after calving. Multiparous cows had a significantly higher response in DMI than primiparous cows from week 3 to weeks $5+6(1.7 \pm 0.4$ v. $0.2 \pm 0.5 \mathrm{~kg} \mathrm{DM})$ for cows on treatment $\mathrm{HNH} / \mathrm{HHH}$.
Physiological parameters in blood, milk and liver Generally, few physiological parameters were affected by treatments (Tables 3 and 4). Thus, looking at responses from week 3 to weeks $5+6$, only glucose was significantly affected by treatment for NHN $v$. NNN. When cows on treatment NHN changed from diet $\mathrm{N}$ to $\mathrm{H}$ in week 4 , a positive glucose response occurred compared with cows on treatment NNN (Table 4). Glucose was also affected when cows on treatment $\mathrm{HNH}$ shifted from diet $\mathrm{N}$ to $\mathrm{H}$ in week 7, resulting in an increased positive glucose response compared with cows on treatment $\mathrm{HHH}$ (Table 3). Cows on treatment NHN also responded differently from their controls in NEFA when changing diet in week 7 (Table 4). However, no treatment effects were obtained for BHB in blood and milk at any times. Likewise, no significant responses were seen for liver TAG and glycogen in weeks 4 or 6 for cows on either treatment HNH or treatment NHN. Multiparous cows had a significantly higher response in plasma BHB $(0.05 \pm 0.04$ v. $-0.14 \pm 0.05 \mathrm{mmol} / \mathrm{l})$ and lower response in NEFA $(-140 \pm 22 \mathrm{v} .-49 \pm 30 \mu \mathrm{eq} / \mathrm{l})$ than primiparous cows from week 3 to week $5+6$ for cows on treatment $\mathrm{HNH} / \mathrm{HHH}$.

The covariates were significant for most physiological parameters, which means that the response of a given metabolite was related to the starting level, i.e. the level 
Nielsen, Friggens, Larsen, Andersen, Nielsen and Ingvartsen

Table 3 Responses (least square mean \pm S.E.) in production and metabolic variables when cows changed diet (HNH) in weeks 4 and 7 after calving compared with cows remaining on the same diet for the first 9 weeks of lactation $(\mathrm{HHH})^{\dagger}$

\begin{tabular}{|c|c|c|c|c|c|c|}
\hline \multirow[b]{2}{*}{ Variable } & \multicolumn{2}{|c|}{ Response from weeks 3 to $5+6$} & \multirow[b]{2}{*}{$\mathrm{H}$ to $\mathrm{N}^{\ddagger}$} & \multicolumn{3}{|c|}{ Significance } \\
\hline & $\mathrm{HHH}$ & $\mathrm{HNH}$ & & Treatment & Parity & Covariate \\
\hline DMI (kg/day) & $2.0 \pm 0.4$ & $-0.1 \pm 0.4$ & -2.1 & ** & * & ** \\
\hline DE (MJ/day) & $28 \pm 6$ & $-10 \pm 6$ & -38 & $* * *$ & * & ** \\
\hline Milk yield (kg/day) & $2.6 \pm 0.9$ & $-0.4 \pm 0.9$ & -3.0 & * & & \\
\hline ECM (kg/day) & $0.6 \pm 0.8$ & $-1.2 \pm 0.9$ & -1.8 & & & * \\
\hline Milk fat $(\mathrm{g} / \mathrm{kg})$ & $-3.0 \pm 1.8$ & $-1.7 \pm 1.9$ & 1.3 & & & \\
\hline Milk protein (g/kg) & $-1.3 \pm 0.6$ & $-2.6 \pm 0.7$ & -1.3 & & & \\
\hline Milk lactose (g/kg) & $0.3 \pm 0.6$ & $-0.6 \pm 0.6$ & -0.9 & & & $* * *$ \\
\hline Blood glucose (mmol/l) & $0.21 \pm 0.05$ & $0.08 \pm 0.06$ & -0.13 & & & * \\
\hline Blood NEFA ( $\mu$ eq/l) & $-118 \pm 26$ & $-70 \pm 26$ & 48 & & * & $* * *$ \\
\hline Blood BHB (mmol/l) & $-0.06 \pm 0.05$ & $-0.03 \pm 0.05$ & 0.03 & & * & $* * *$ \\
\hline Milk BHB ( $\mu \mathrm{mol} / \mathrm{l})$ & $-9 \pm 5$ & $2 \pm 5$ & 11 & & & $* * *$ \\
\hline Liver TAG ( $\mu \mathrm{mol} / \mathrm{g})$ & $-2.2 \pm 1.2$ & $-3.8 \pm 1.3$ & -1.6 & & & ** \\
\hline \multirow[t]{2}{*}{ Liver glycogen $(\mu \mathrm{mol} / \mathrm{g})$} & $2.1 \pm 13.8$ & $8.3 \pm 14.8$ & 6.2 & & & \\
\hline & \multicolumn{2}{|c|}{ Response from weeks 6 to $8+9$} & $\mathrm{~N}$ to $\mathrm{H}^{\ddagger}$ & & & \\
\hline DMI (kg/day) & $1.8 \pm 0.5$ & $2.5 \pm 0.5$ & 0.7 & & & \\
\hline DE (MJ/day) & $24 \pm 7$ & $45 \pm 7$ & 21 & * & & \\
\hline Milk yield (kg/day) & $-0.8 \pm 0.9$ & $0.6 \pm 0.9$ & 1.4 & & & \\
\hline ECM (kg/day) & $-2.3 \pm 0.9$ & $-1.6 \pm 0.9$ & 0.7 & & & $* *$ \\
\hline Milk fat (g/kg) & $-3.0 \pm 1.2$ & $-2.4 \pm 1.2$ & 0.6 & & & \\
\hline Milk protein (g/kg) & $0.1 \pm 0.8$ & $1.3 \pm 0.8$ & 1.2 & & & \\
\hline Milk lactose (g/kg) & $-0.3 \pm 0.1$ & $-0.1 \pm 0.1$ & 0.2 & & & ** \\
\hline Blood glucose $(\mathrm{mmol} / \mathrm{l})$ & $0.07 \pm 0.04$ & $0.22 \pm 0.04$ & 0.15 & * & & * \\
\hline Blood NEFA ( $\mu \mathrm{eq} / \mathrm{l})$ & $-76 \pm 13$ & $-78 \pm 13$ & -2 & & & $* * *$ \\
\hline Blood BHB (mmol/l) & $-0.01 \pm 0.03$ & $-0.05 \pm 0.03$ & -0.04 & & & $* * *$ \\
\hline Milk BHB ( $\mu \mathrm{mol} / \mathrm{l})$ & $3 \pm 4$ & $-6 \pm 4$ & -9 & & & $* * *$ \\
\hline Liver TAG $(\mu \mathrm{mol} / \mathrm{g})$ & $-9.4 \pm 1.4$ & $-9.0 \pm 1.5$ & 0.4 & & & $* * *$ \\
\hline Liver glycogen $(\mu \mathrm{mol} / \mathrm{g})$ & $30.5 \pm 11.7$ & $27.6 \pm 13.2$ & -2.9 & & & $* * *$ \\
\hline
\end{tabular}

${ }^{\dagger}$ Cows fed HHH had access to a 'high' energy density diet for the first 9 weeks of lactation, while cows fed HNH changed from high to a 'normal' energy density diet at week 4 of lactation and then again changed back to the high energy density diet at week 7 of lactation. Thus, responses were calculated as: (weeks $5+6$ - week 3) and (weeks $8+9$ - week 6) except for liver triacylglycerol (TAG) and glycogen where responses were calculated as: (week 4 - week 3) and (week 6 - week 3). Abbreviations used: $\mathrm{DMI}=$ dry-matter intake; $\mathrm{DE}=$ digestible energy; $\mathrm{ECM}=$ energy-corrected milk; NEFA = non-esterified fatty acids; $\mathrm{BHB}=$ betahydroxybutyrate.

${ }^{\ddagger}$ Difference in response between treatments $\mathrm{HHH}$ and $\mathrm{HNH}$.

of that metabolite in weeks 3 and 6 (only week 3 for liver TAG and glycogen). This is illustrated in Figure 4 for NEFA, where individual responses from week 3 to weeks $5+6$ are plotted for treatments $\mathrm{HHH}$ and $\mathrm{HNH}$. Figure 4 shows that the higher NEFA is in week 3 after calving the more negative a response, i.e. a cow with high levels of NEFA in week 3 will show a rapid decrease in NEFA from weeks 3 to $5+6$ compared with a cow with lower levels in week 3 .

\section{Discussion}

Dry-matter intake

The concentrate/roughage ratio was $30 / 70$ and $48 / 52$ for diet $\mathrm{N}$ and $\mathrm{H}$ (Table 1), respectively, which corresponds to a difference in concentrates of 18 percentage units between diets. This is considered a moderate difference compared with trials where a difference in concentrates of 30-50 percentage units between diets has been used (Nachtomi et al., 1991; Dhiman et al., 1993; Andersen et al., 2004). The moderate difference between diet $\mathrm{H}$ and $\mathrm{N}$ caused significant differences in responses of $2.1 \mathrm{~kg}$ DM in week $5+6(2.0 v$. -0.1 and 1.3 v. 3.4, Tables 3 and 4), i.e. the changes in DMI from $\mathrm{H}$ to $\mathrm{N}$ and $\mathrm{N}$ to $\mathrm{H}$ were symmetrical. This suggests that cows were mainly physically restricted in their DMI by diet $\mathrm{N}$ compared with diet $\mathrm{H}$. The responses in DMI from weeks 6 to $8+9$ also indicated a physical restriction, although the positive response in DMI $(0.7 \mathrm{~kg}$, Table 3$)$ was not significant for treatment $\mathrm{HNH} v$. HHH. Normally, it is recommended that changes in the diet should be avoided, especially in early lactation (Friggens et al., 2004; Ingvartsen, 2006) but the moderate changes in the diet did not cause any problems in this experiment. Thus, the cows seemed robust and responded in their DMI as expected, i.e. increased their DMI when 
Table 4 Responses (least-square mean \pm S.E.) in production and metabolic variables when cows change diet (NHN) in weeks 4 and 7 after calving compared with cows remaining on the same diet for the first 9 weeks of lactation (NNN) ${ }^{\dagger}$

\begin{tabular}{|c|c|c|c|c|c|c|}
\hline \multirow[b]{2}{*}{ Variable } & \multicolumn{2}{|c|}{ Response from weeks 3 to $5+6$} & \multirow[b]{2}{*}{$\mathrm{N}$ to $\mathrm{H}^{\ddagger}$} & \multicolumn{3}{|c|}{ Significance } \\
\hline & NNN & NHN & & Treatment & Parity & Covariate \\
\hline DMI (kg/day) & $1.3 \pm 0.7$ & $3.4 \pm 0.6$ & 2.1 & * & & \\
\hline DE (MJ/day) & $24 \pm 10$ & $55 \pm 9$ & 31 & * & & \\
\hline Milk yield (kg/day) & $1.8 \pm 1.1$ & $3.3 \pm 1.1$ & 1.5 & & & \\
\hline ECM (kg/day) & $1.6 \pm 1.0$ & $1.6 \pm 1.3$ & 0 & & & \\
\hline Milk fat (g/kg) & $-2.9 \pm 1.7$ & $-6.9 \pm 2.0$ & -4 & & & ** \\
\hline Milk protein (g/kg) & $-2.4 \pm 1.0$ & $0.1 \pm 1.2$ & 2.5 & & & \\
\hline Milk lactose (g/kg) & $0.3 \pm 0.5$ & $0.8 \pm 0.6$ & 0.5 & & & $* * *$ \\
\hline Blood glucose (mmol/l) & $-0.08 \pm 0.06$ & $0.29 \pm 0.06$ & 0.37 & $* * *$ & & $* * *$ \\
\hline Blood NEFA ( $\mu \mathrm{eq} / \mathrm{l})$ & $-192 \pm 35$ & $-146 \pm 33$ & 46 & & & ** \\
\hline Blood BHB (mmol/l) & $-0.08 \pm 0.05$ & $-0.14 \pm 0.04$ & -0.06 & & & *** \\
\hline Milk BHB $(\mu \mathrm{mol} / \mathrm{l})$ & $-23 \pm 6$ & $-29 \pm 6$ & -6 & & & $* * *$ \\
\hline Liver TAG $(\mu \mathrm{mol} / \mathrm{g})$ & $-4.6 \pm 2.0$ & $-5.7 \pm 1.7$ & -1.1 & & & \\
\hline \multirow[t]{2}{*}{ Liver glycogen $(\mu \mathrm{mol} / \mathrm{g})$} & $0.1 \pm 18.4$ & $40.5 \pm 17.9$ & 40.4 & & & ** \\
\hline & \multicolumn{2}{|c|}{ Response from week 6 to $8+9$} & $\mathrm{H}$ to $\mathrm{N}^{\ddagger}$ & & & \\
\hline DMI (kg/day) & $1.6 \pm 0.7$ & $-0.9 \pm 0.6$ & -2.5 & * & & \\
\hline DE (MJ/day) & $21 \pm 10$ & $-21 \pm 9$ & 42 & ** & & \\
\hline Milk yield (kg/day) & $-0.8 \pm 1.3$ & $-2.3 \pm 1.2$ & -1.5 & & & \\
\hline ECM (kg/day) & $-0.6 \pm 1.4$ & $-2.2 \pm 1.2$ & -1.6 & & & \\
\hline Milk fat (g/kg) & $-1.8 \pm 2.1$ & $2.9 \pm 1.8$ & 4.7 & & & \\
\hline Milk protein (g/kg) & $0.8 \pm 1.0$ & $1.2 \pm 0.9$ & 0.4 & & & \\
\hline Milk lactose (g/kg) & $0.2 \pm 0.7$ & $1.1 \pm 0.6$ & 0.9 & & & $* * *$ \\
\hline Blood glucose $(\mathrm{mmol} / \mathrm{l})$ & $0.18 \pm 0.06$ & $0.05 \pm 0.05$ & -0.13 & & & \\
\hline Blood NEFA ( $\mu \mathrm{eq} / \mathrm{l})$ & $-105 \pm 15$ & $-57 \pm 14$ & 48 & * & & $* * *$ \\
\hline Blood BHB (mmol/l) & $-0.03 \pm 0.07$ & $0.04 \pm 0.06$ & 0.07 & & & * \\
\hline Milk BHB ( $\mu \mathrm{mol} / \mathrm{l})$ & $1 \pm 6$ & $4 \pm 6$ & 3 & & & * \\
\hline Liver TAG $(\mu \mathrm{mol} / \mathrm{g})$ & $-10.9 \pm 1.6$ & $-11.9 \pm 1.5$ & -1 & & & $* * *$ \\
\hline Liver glycogen $(\mu \mathrm{mol} / \mathrm{g})$ & $51.9 \pm 13.6$ & $44.9 \pm 12.6$ & -7 & & * & $* * *$ \\
\hline
\end{tabular}

${ }^{\dagger}$ Cows fed NNN had access to a 'normal' energy density diet for the first 9 weeks of lactation, while cows fed NHN changed from normal to a 'high' energy density diet at week 4 of lactation and then again changed back to the normal energy density diet at week 7 of lactation. Thus, responses were calculated as: (weeks $5+6-$ week 3) and (weeks $8+9$ - week 6) except for liver triacylglycerol (TAG) and glycogen where responses were calculated as: (week $4-$ week 3) and (week 6 - week 3). Abbreviations used: DMI = dry-matter intake; $\mathrm{DE}=$ digestible energy; $\mathrm{ECM}=$ energy-corrected milk; NEFA = non-esterified fatty acids; $\mathrm{BHB}=$ beta-hydroxybutyrate.

${ }^{\ddagger}$ Difference in response between treatments NNN and NHN.

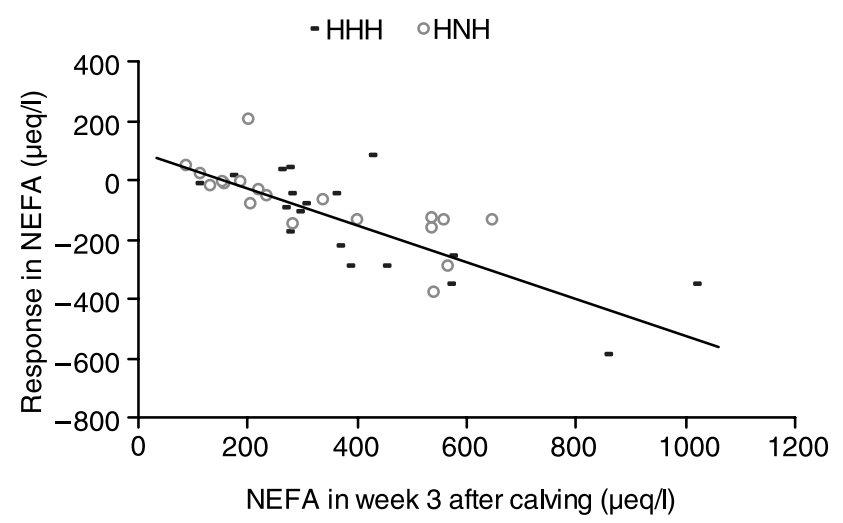

Figure 4 The relationship between NEFA in week 3 after calving and the change in NEFA from 3 to week $5+6$. Data are shown for cows fed a TMR with a high energy density $(\mathrm{HHH})$ and for cows shifting from a high to a normal energy density TMR (HNH) in week 4 . The regression line illustrates the significant negative relationship between NEFA measured in week 3 and weeks $5+6$. changing from diet $\mathrm{N}$ to $\mathrm{H}$ and vice versa. An explanation for this robustness could be that the feed ingredients were the same for both TMRs, i.e. rumen microbes did not have to adapt to new feed components, which has been proposed as a risk for reduced feed intake and impaired metabolism and health (Goff and Horst, 1997).

Milk yield

The changes in DMI and DE were reflected in milk yield, although milk yield responses were only significant when cows changed from $\mathrm{H}$ to $\mathrm{N}$ for treatment $\mathrm{HNH}$ (Table 3). It was surprising that the significant differences in feed responses of more than $2 \mathrm{~kg}$ DM per day (1.3 v. 3.4 and 1.6 v. -0.9 , Table 4) between treatment NNN and NHN only caused non-significant differences in responses for milk yield of $1.5 \mathrm{~kg}$ (Table 4). Assuming that the changes observed in DE would be reflected $100 \%$ in milk yield, one could expect that the change in DE of $31 \mathrm{MJ} /$ day when 
changing from $\mathrm{N}$ to $\mathrm{H}$ (Table 4) could alter ECM yield by $5.1 \mathrm{~kg}$. However, as seen in Tables 3 and 4 this was not the case. This energy calculation was based on conversion ratios of 0.82 from $D E$ to $M E$ and 0.63 from $M E$ to $N E_{\mid}$and an energy content of $3.14 \mathrm{MJ} / \mathrm{kg}$ milk (Agricultural and Food Research Council, 1993).

The response in ECM yield due to the increase in DMI was even more limited for treatment NHN in weeks $5+6$ than expected (Table 4). Thus, the additional intake of $2.1 \mathrm{~kg} \mathrm{DM}$ for cows on treatment NHN in weeks $5+6$ compared with cows on treatment NNN was surprisingly not used for milk production, but to improve energy balance. This is supported by the significant positive glucose response for treatment NHN in weeks $5+6$ and the fact that the absolute levels of glucose and NEFA were higher and lower, respectively, in weeks 4 to 6 for NHN compared with NNN. An explanation for this prioritisation of restoration of body reserves could be that these cows had a low body condition score (BCS) at calving, since such cows are likely not to lose - or at least not lose much - body condition (Broster and Broster, 1998). However, this was not the case since BCS data (data not shown) obtained during the first 3 weeks of lactation were quite similar for the four feeding regimes (range: 3.38 to $3.50 \mathrm{BCS}$ units on a 1 to 5 scale).

The lack of a significant positive response in milk yield in weeks $8+9$ for treatment HNH could indicate that it is difficult to get milk yield 'back on track' after a change in feeding that first decreases milk yield and then afterwards attempts to stimulate milk yield. An explanation might be that the response in DMI was not high enough compared with cows on treatment HHH (2.5 v. $1.8 \mathrm{~kg} /$ day, Table 3) to cause a significant increase in milk yield or that a downregulation of glucose uptake by the mammary glands occurred. The significant positive glucose response in cows that changed from diet $\mathrm{N}$ to $\mathrm{H}$ on treatment $\mathrm{HNH}$ suggests that glucose was available for the mammary glands. Because mammary uptake of glucose is highly correlated to milk yield (Nielsen and Riis, 1993), a down-regulation in the mammary uptake of glucose might have taken place during the diet change in weeks 4 to 6 and thereby reduced the potential for an increased milk yield. It has been shown in dairy goats that mammary uptake of glucose decreases with lactation stage (Madsen et al., 2005) and is likely to be caused by down-regulation of glucose transport proteins in the secretory cells (Nielsen et al., 2001). Somehow this down-regulation might have been stimulated when cows experienced a decrease in energy density during weeks 4 to 6 .

\section{Physiological parameters}

The profiles for NEFA and glucose in early lactation are in accordance with previous studies (Nachtomi et al., 1991; Andersen et al., 2004) and likewise for liver TAG and glycogen (Andersen et al., 2002b), except that liver glycogen was relatively high in week 3 after calving compared with Andersen et al. (2002b). However, the level of BHB in blood and, especially in milk, during the first 9 weeks of lactation was relatively constant compared with other experiments (Suriyasathaporn et al., 2000; Andersen et al., 2004). This could be explained by the fact that no cows with clinical ketosis or displaced abomasums were included in our results. Because BHB is produced both in the liver and in the rumen epithelium (Kristensen, 2005), it is difficult to know whether there actually was an effect of changing diets on hepatic ketogenesis. E.g. the positive response of $3.4 \mathrm{~kg} \mathrm{DMl}$ for treatment NHN in weeks $5+6$ could have caused an increased supply of dietary BHB to the peripheral blood, but at the same time the decrease in NEFA could have reduced hepatic ketogenesis and thereby counteracted the effect of the increased DMI.

Glucose was the only metabolite responding consistently to the shifts in diet energy density. When cows changed from diet $\mathrm{N}$ to $\mathrm{H}$ their glucose concentration increased relative to the control cows (NNN and $\mathrm{HHH}$ ) and when the change was made from $\mathrm{H}$ to $\mathrm{N}$, glucose concentration was reduced relative to their respective control groups, although not significant in all instances. This suggests that the changes in the energy density of the diet had some impact on the glucose status of the cows. However, apart from the effects on glucose and NEFA in weeks $8+9$ for treatment NHN, the moderate changes in diet energy density did not affect other metabolic parameters. The moderate changes in metabolic parameters and the changes in milk yield according to DMI indicate that a homeostatic regulation was taken place in the cows that changed diet.

We expected to find more pronounced responses in the physiological parameters to changes in energy density in lactation weeks $5+6$ compared with weeks $8+9$ because the variation in for instance NEFA, BHB and glucose is highest in the first few weeks after calving (Ingvartsen et al., 2003). In other words cows might had been more susceptible to shifts in energy density in week 3 compared with week 6, where the mobilisation of body reserves is relatively low. However, this experiment could not support the hypothesis that cows are more susceptible to changes in the energy density in weeks $5+6$ compared with weeks $8+9$.

A lag effect for the relation between BHB in blood and BHB in milk was apparent since BHB in blood peaked in week 2 while it first peaked in week 3 for BHB in milk (Figure 2). Mammary uptake of BHB mainly depends on arterial supply (Madsen et al., 2005) and therefore one could expect BHB in blood and milk to peak at the same time. However, BHB is metabolised in the mammary cells and therefore $B H B$ in milk does not directly have to reflect BHB in blood, but knowledge is lacking in terms of what determines how big a proportion that is oxidised, used in milk fat synthesis or excreted into milk.

It was surprising that the concentration of NEFA was so different between groups of cows that were fed and managed equally in the dry period and the first 3 weeks after calving. Thus, looking at groups $\mathrm{HHH}$ and $\mathrm{HNH}$, which included 20 cows each, there was an average difference of 
approximately $120 \mu \mathrm{eq} / \mathrm{l}$ in weeks 2 and 3 after calving (Figure 2). Outliers or diseased animals in any of the groups could not explain this difference. Judging from all the physiological variables in the first 3 weeks after calving, it seems clear that cows in group $\mathrm{HHH}$ were more metabolically challenged than cows in group $\mathrm{HNH}$ as evidenced by higher levels of plasma NEFA, BHB and liver TAG and lower plasma levels of glucose and liver glycogen.

\section{Use of metabolic measures for individual feeding}

One ultimate goal would be to use information from metabolic measures to 'optimise' the diet for an individual cow or group of cows in order to prevent clinical diseases or improve nutrient efficiency. An example, at least in Denmark, is milk urea, which is used by advisors to adjust the protein content of the diet for a group of cows or the whole herd. In this experiment, the energy density of a diet was examined as a modulator of metabolic parameters. In situations where blood (or milk) measurements show that cows have 'risky' levels of BHB, NEFA or glucose, it would be beneficial if an increased energy density in the diet could 'correct' the levels of these metabolites and thereby decrease the risk of a metabolic disease. However, as mentioned, the results from this trial suggest that, except from glucose, metabolic parameters are not easily changed by moderate changes in the energy density of an ad libitum fed TMR.

\section{Conclusion}

This trial showed that early lactating cows responded to changes in the energy density of an ad libitum diet by increasing or decreasing their DMI and generally adjusted milk yield accordingly. The adjustment of milk yield according to DMI explains why there were limited effects on the metabolic status of the cows, and hence metabolic diseases are not likely to develop as a result of such moderate dietary changes. Except for plasma glucose, metabolic parameters including plasma NEFA and BHB, liver TAG and glycogen and milk BHB did not respond to changes in the energy density of fed diet. The results therefore suggest that the metabolic status of early lactating cows is relatively robust towards moderate changes in the energy density of the diet and that such changes do not decrease milk yield permanently.

\section{Acknowledgements}

Dorte Bossen, Lene Munksgaard and Martin Riis Weisbjerg are greatly appreciated for their help with coordination of this experiment. Thanks to Ellen-Margrethe Vestergaard for sampling of liver tissue and Lene Niklassen, Jens Balslev Clausen and Carsten Berthelsen for their analyses of liver, milk and blood samples. The help of Connie Hårbo Middelhede and Martin Bjerring with extracting feed and milk data is greatly appreciated. Karin Vikkelsø Østergaard is thanked for her linguistic corrections of the manuscript.

\section{References}

Agricultural and Food Research Council. 1993. Energy and protein requirements of ruminants. $C A B$ International, Wallingford.

Andersen JB, Friggens NC, Larsen T, Vestergaard M and Ingvartsen KL 2004. Effect of energy density in the diet and milking frequency on plasma metabolites and hormones in early lactating dairy cows. Journal of Veterinary Medicine 51, 52-57.

Andersen JB, Ingvartsen KL and Larsen T 2002a. [The possibility of quantitative analysis of cattle plasma on-farm.] Grøn Viden no. 26.

Andersen JB, Larsen T, Nielsen MO and Ingvartsen KL 2002b. Effect of energy density in the diet and milking frequency on hepatic long chain fatty acid oxidation in early lactating dairy cows. Journal of Veterinary Medicine 49, 177-183.

Andersen JB, Madsen TG, Larsen T, Ingvartsen KL and Nielsen MO 2005. The effects of dry period versus continuous lactation on metabolic status and performance in periparturient cows. Journal of Dairy Science 88, 3530-3541.

Broster WH and Broster VJ 1998. Body score of dairy cows. Journal of Dairy Research 65, 155-173.

Dhiman TR, Cadorniga C and Satter LD 1993. Protein and energy supplementation of high alfalfa silage diets during early lactation. Journal of Dairy Science 76, 1945-1959.

Drackley JK, Veenhuizen JJ, Richard MJ and Young JW 1991. Metabolic changes in blood and liver of dairy cows during either feed restriction or administration of 1,3-butanediol. Journal of Dairy Science 74, 4254-4264.

Friggens NC, Andersen JB, Larsen T, Aaes 0 and Dewhurst RJ 2004. Priming the dairy cow for lactation: a review of dry cow feeding strategies. Animal Research 53, 453-473.

Friggens NC, Emmans GC, Kyriazakis I, Oldham JD and Lewis M 1998. Feed intake relative to stage of lactation for dairy cows consuming total mixed diets with a high or low ratio of concentrate to forage. Journal of Dairy Science 81, 2228-2239.

Friggens NC and Rasmussen MD 2001. Milk quality assessment in automatic milking systems. Accounting for the effects of variable intervals between milkings on milk composition. Livestock Production Science 73, 45-54.

Goff JP and Horst RL 1997. Physiological changes at parturition and their relationship to metabolic disorders. Journal of Dairy Science 80, 1260-1268.

Harano Y, Ohtsuki M, Ida M, Kojima H, Harada M, Okanishi T, Kashiwagi A, Ochi Y, Uno $S$ and Shigeta $Y$ 1985. Direct automated assay method for serum or urine levels of ketone bodies. Clinical Chimica Acta 151, 177-183.

Herdt TH and Emery RS 1992. Therapy of diseases of ruminant intermediary metabolism. Veterinary Clinics of North America. Food Animal Practice 8, 91-106.

Ingvartsen KL 2006. Feeding- and management-related diseases in the transition cow: physiological adaptations around calving and strategies to reduce feeding-related diseases. Animal Feed Science and Technology 126, 175-213.

Ingvartsen KL, Dewhurst RJ and Friggens NC 2003. On the relationship between lactational performance and health: is it yield or metabolic imbalance that cause production diseases in dairy cattle? Livestock Production Science 83, 277-308.

Kristensen NB 2005. Splanchnic metabolism of volatile fatty acids in the dairy cow. Animal Science 80, 3-10.

Larsen T and Nielsen NI 2005. Fluorometric determination of $\beta$-hydroxybutyrate in milk and blood plasma. Journal of Dairy Science 88, 2004-2009.

McNamara S, O'Mara FP, Rath M and Murphy JJ 2003. Effects of different transition diets on dry matter intake, milk production and milk composition in dairy cows. Journal of Dairy Science 86, 2397-2408.

Madsen TG, Nielsen L and Nielsen MO 2005. Mammary nutrient uptake in response to dietary supplementation of rumen protected lysine and methionine in late and early lactating dairy goats. Small Ruminant Research 56, 151-164.

Møller J, Thøgersen R, Helleshøj ME, Weisbjerg MR, Søegaard K and Hvelplund T 2005. [Table of feedstuffs.] Report no. 112. Danish Cattle, Århus, Denmark

Mottram T, Velasco-Garcia M, Berry $\mathrm{P}$, Richards $\mathrm{P}$, Ghesquiere J and Masson L'2002. Automatic on-line analysis of milk constituents (urea, ketones, enzymes and hormones) using biosensors. Comparative Clinical Pathology 11, 50-58. 
Nachtomi E, Halevi A, Bruckental I and Amir S 1991. Energy-protein intake and its effect on blood metabolites of high producing dairy cows. Canadian Journal of Animal Science 71, 401-407.

Nielsen NI, Friggens NC, Chagunda MGG and Ingvartsen KL 2005. Predicting risk of ketosis in dairy cows using in-line measurements of beta-hydroxybutyrate: a biological model. Journal of Dairy Science 88, 2441-2453.

Nielsen NI, Ingvartsen KL and Larsen T 2003. Diurnal variation and the effect of feed restriction on plasma and milk metabolites in TMR-fed dairy cows. Journal of Veterinary Medicine 50, 88-97.

Nielsen MO, Madsen TG and Hedeboe AM 2001. Regulation of mammary glucose uptake in goats: role of mammary gland supply, insulin, IGF-1 and synthetic capacity. Journal of Dairy Research 68, 337-349.

Nielsen MO and Riis PM 1993. Somatotropin, insulin-like growth factor-I and the mammary gland in regulation of nutrient and energy metabolism during early lactation. Acta Veterinaria Scandinavica 89, (suppl.) 47-54.
Perkins N, Gooijer L, Leslie K, Duffield T, Leblanc S and Vernooy E 2005. Evaluation of an on-site test for NEFA in bovine serum. Accessed on November 9, 2005; http://www.vetdx.biz/user/DVM\%20NEFA\%20Poster.pdf

Sjaunja LO, Baevre L, Junkkarinen L, Pedersen J and Setälä J, 1990. A Nordic proposal for an energy corrected milk (ECM) formula. In Proceedings of 27th session of International Committee of Recording and Productivity of Milk Animals, 2-6 July, Paris, pp. 156-157.

Statistical Analysis Systems Institute 1999. SAS Online Doc ${ }^{\circledR}$, version 8. SAS Institute Inc., Cary, NC.

Suriyasathaporn W, Heuer C, Noordhuizen-Stassen EN and Schukken YH 2000. Hyperketonemia and the impairment of udder defence: a review. Veterinary Research 31, 397-412.

Veenhuizen JJ, Drackley JK, Richard MJ, Sanderson TP, Miller LD and Young JW 1991. Metabolic changes in blood and liver during development and early treatment of experimental fatty liver and ketosis in cows. Journal of Dairy Science 74, 4238-4253. 